\title{
Estimation and characterization of PCDD/Fs, dl-PCBs, PCNs, HxCBz and PeCBz emissions from magnesium metallurgy facilities in China
}

\author{
Zhiqiang Nie, Minghui Zheng*, Wenbin Liu, Bing Zhang, Guorui Liu, Guijin Su, Pu Lv, Ke Xiao \\ State Key Laboratory of Environmental Chemistry and Ecotoxicology, Research Center for Eco-Environmental Sciences, Chinese Academy of Sciences, \\ P.O. Box 2871, Beijing 100085, China
}

\section{A R T I C L E I N F O}

\section{Article history:}

Received 14 February 2011

Received in revised form 18 August 2011

Accepted 22 September 2011

Available online 22 October 2011

\section{Keywords:}

Unintentional POPs

Magnesium smelting

Emissions factor

Inventory

\begin{abstract}
A B S T R A C T
Magnesium production is considered to be one potential source of unintentional persistent organic pollutants (unintentional POPs). However, studies on the emissions of unintentional POPs from magnesium metallurgy are still lacking. Emissions of unintentional POPs, such as polychlorinated dibenzo-p-dioxins/ dibenzofurans ( $\mathrm{PCDD} / \mathrm{Fs}$ ), dioxin-like polychlorinated biphenyls (dl-PCBs), polychlorinated naphthalenes (PCNs), hexachlorobenzene $(\mathrm{HxCBz})$ and pentachlorobenzene $(\mathrm{PeCBz})$ are covered under the Stockholm Convention. In this study, these emissions were investigated through a magnesium smelting process. Stack gas and fly ash samples from a typical magnesium plant in China were collected and analyzed to estimate the emissions of unintentional POPs from magnesium metallurgy. Emissions factors of $412 \mathrm{ng} \mathrm{TEQ} \mathrm{t}^{-1}$ for PCDD/Fs, $18.6 \mathrm{ng} \mathrm{TEQ} \mathrm{t}^{-1}$ for dl-PCBs, $3329 \mu \mathrm{g} \mathrm{t}^{-1}$ for PCNs, $820 \mu \mathrm{g} \mathrm{t}^{-1}$ for $\mathrm{HxCBz}$, and $1326 \mu \mathrm{g} \mathrm{t}^{-1}$ for PeCBz were obtained in 2009. Annual emissions from magnesium metallurgy in China were estimated to be $0.46 \mathrm{~g}$ WHO-TEQ for PCDD/Fs and dl-PCBs, $1651 \mathrm{~g}$ for PCNs, $403 \mathrm{~g}$ for HxCBz and $653 \mathrm{~g}$ for $\mathrm{PeCBz}$, respectively.
\end{abstract}

(c) 2011 Elsevier Ltd. All rights reserved.

\section{Introduction}

Some of the most toxic pollutants to humans and the environment are polychlorinated dibenzo-p-dioxin and dibenzofurans (PCDD/Fs). The threats of these toxins and other unintentional persistent organic pollutants (unintentional POPs), such as polychlorinated biphenyls ( $\mathrm{dl}-\mathrm{PCBs})$, hexachlorobenzene $(\mathrm{HxCBz})$, pentachlorobenzene $(\mathrm{PeCBz})$ and polychlorinated naphthalenes (PCNs), have received much attention worldwide. As a result, the Stockholm Convention on POPs was adopted in May 2001, and came into effect on May 17th, 2004. This convention aimed to control and reduce further environmental exposure of unintentional POPs at regional and global levels. For example, the Stockholm Convention states that inventories of unintentional POPs release have to be established and maintained as evidence of continuous reduction of unintentional POPs release and improved human and environmental protection against unintentional POPs (UNEP Chemicals, 2005; Fiedler, 2007). Many studies have shown that PCDD/Fs, dl-PCBs, PCNs, HxCBz and PeCBz can be formed in thermal processes, such as waste incineration, metal smelting, coke production and chemical manufacturing (Dyke and Amendola, 2007; Ni et al., 2009; Ba et al., 2010; Liu et al., 2010). However,

\footnotetext{
* Corresponding author. Tel.: +86 10 62849172; fax: +86 1062923563 .

E-mail address: zhengmh@rcees.ac.cn (M. Zheng).
}

considerable uncertainties exist with regard to the fluxes of unintentional POPs into the environment for some sources.

In 2007, China established the National Implementation Plan (China's NIP, 2007) for the Stockholm Convention on persistent organic pollutants. The NIP states that in 2004, China produced a total PCDD/Fs emission from all sources of $10.2 \mathrm{~kg}$ toxic equivalent (TEQ). Of this amount $5 \mathrm{~kg}$ TEQ were released directly to the air and $5 \mathrm{~kg}$ TEQ were released as residues (China's NIP, 2007). PCDD/Fs released from ferrous and non-ferrous metal production industries were the biggest component, accounting for $45.6 \%$ of the total. This amount was followed by power and heat generation and waste incineration sources. Studies on the emissions of unintentional POPs from non-ferrous metal metallurgies, especially the magnesium industry, are lacking, although some research exists on unintentional POPs emissions from smelting processes, such as secondary copper, zinc, aluminum and lead smelting ( $\mathrm{Li}$ et al., 2007; Ba et al., 2009a,b). In the PCDD/Fs release toolkit section of the release inventory, magnesium production is considered to be a potential unintentional POPs source (UNEP Chemicals, 2005). However, there are very little data regarding the release of unintentional POPs to the atmosphere from magnesium industries. Compared with PCDD/Fs and dl-PCBs, investigations on PCNs, PeC$\mathrm{Bz}$ and $\mathrm{HxCBz}$ emissions to the air from magnesium smelting processes are poorly reported. Such information is limited to unintentional POPs monitoring studies in environmental matrices, such as water, sediments and biota around magnesium plants 
(Tolley and Blais, 2007; Ishaq et al., 2009). Thus, the development of unintentional POPs inventories from magnesium smelting processes in China is crucial for evaluation of unintentional POPs releases from magnesium industries worldwide.

The rate of magnesium production has increased greatly in recent years. China is the largest primary magnesium producing country in the world, and the raw materials for the magnesium industry come primarily from sources of magnesite, dolomite, lake brines and seawater (Chen and Shi, 1995). In 2008, the annual production of primary magnesium reached about $558 \times 10^{3}$ tons, which was about $84 \%$ of the global magnesium production (Bao and Zhou, 2009). Nearly $99 \%$ of the primary magnesium production of China is produced using the Pidgeon process (China's NIP, 2007). This process was invented in the 1940s in Canada, and has the advantages of being a short technical process, requires a low investment input, is a fast process, and has a low production cost. After considerable investigation, this magnesium process, with nearly the same technology and air pollution control devices (APCDs), was implemented throughout China. The estimation of unintentional POPs emissions factors and total release from the magnesium smelting process in China were obtained from a typical magnesium smelting plant.

Pidgeon is a typical thermal process, which consists of an oxidation, reduction and casting process, and uses dolomite as the raw material. Briefly, dolomite is transported to the magnesium plant where it is calcined $\left(\mathrm{CaCO}_{3} \cdot \mathrm{MgCO}_{3}\right.$ theat $\left.\rightarrow \mathrm{CaO} \cdot \mathrm{MgO}+2 \mathrm{CO}_{2}\right)$ and briquetted. These briquettes are fed to a reactor, which is internally heated with coal gas (up to $1200{ }^{\circ} \mathrm{C}$ ) to develop a magnesium vapor $\left(2 \mathrm{CaO} \cdot \mathrm{MgO}+\mathrm{Si}(\mathrm{Fe}) \rightarrow 2 \mathrm{Mg}+\mathrm{Ca}_{2} \mathrm{SiO}_{4}\right)$. Then, the system is water-cooled to $450{ }^{\circ} \mathrm{C}$. Magnesium, in its pure or alloy form, is protected against oxidation by dispersing a sulfur powder. The final product is cast as ingots.

The formation and emissions of unintentional POPs may occur during oxidization of dolomites $(\mathrm{Ox})$ and reduction of oxidized magnesium compounds (Re). Because the casting process involves purely raw materials and high temperature, the formation of unintentional POPs may be ignored. Thus, the release of unintentional POPs may arise mainly from oxidization and reduction of magnesium. In this study, stack gas and fly ash from a typical magnesium plant were sampled several times to identify levels of unintentional POPs emissions, and to produce magnesium profiles during the $\mathrm{Ox}$ and Re stages. Emissions factors of unintentional POPs also were derived and used to estimate emissions of unintentional POPs from the magnesium industry. These data may be used to understand the contribution of unintentional POPs from the magnesium industry, and to develop an emissions inventory of unintentional POPs.

\section{Materials and methods}

\subsection{Sample collection}

In this study, a total of 9 stack gas and 4 fly ash samples were collected from different smelting stages in a typical magnesium smelting plant in China. Six stack gas samples were collected from the oxidation stage at different times to reduce sampling errors. Three stack gas samples were collected from the reduction stage. For each of the two stages, two fly ash samples were collected. The samples were collected from different types of furnace and air pollution control devices (APCDs) within the plant (Table S1).

The stack gas samples were collected with an automatic isokinetic sampling system (Isostack Basic, TCR TECORA, Milan, Italy). The sampling point was set downstream of all air pollution control devices (APCDs). Prior to collection, $\mathrm{O}_{2}$ and $\mathrm{CO}_{2}$ levels were measured in the stack gas using a Testo 355 flue gas analyzer (Testo,
Germany). The sampling system consisted of a filter (25 mm i.d., $90 \mathrm{~mm}$ length, silica glass microfiber thimble, Whatman, UK), a condensing system, and an adsorbing resin (Amberlite XAD-2, Supleco, St. Louis, MS, USA). The resin was spiked with a ${ }^{13} \mathrm{C}_{12}$-labelled EDF-4054 (CIL, MA, USA) internal standard before sampling. Fly ash samples were collected under APCDs.

\subsection{Sample extraction and analysis}

Analysis of PCDD/Fs and dl-PCBs was carried out using US EPA methods 23 and 1668A. Both stack gas and fly ash samples were spiked with ${ }^{13} \mathrm{C}_{12}$-labelled EDF-4053 (CIL, MA, USA) and ${ }^{13} \mathrm{C}_{12}$-labelled 68A-LCS (Wellington Laboratories, Guelph, Canada) extraction standards, respectively. The fly ash samples were selectively pretreated with $1 \mathrm{~mol} \mathrm{~L}^{-1} \mathrm{HCl}$ after being spiked with ${ }^{13} \mathrm{C}_{12^{-}}$ labelled internal standards. Before HRGC/HRMS analysis, ${ }^{13} \mathrm{C}_{12^{-}}$ labelled EDF-4055 (CIL, MA, USA) and ${ }^{13} \mathrm{C}_{12}$-labelled 68A-IS (Wellington Laboratories, Guelph, Canada) mixture standards were added into the corresponding fractions to calculate recovery efficiencies. The sample extraction, cleanup and instrumental analysis for PCDD/Fs and dl-PCBs determination are described in (Ba et al., 2009b).

The HRGC/HRMS method was used for PCNs measurements, and the samples were spiked with a ${ }^{13} \mathrm{C}_{10}$-labelled ECN-5102 (CIL, MA, USA) before extraction. Prior to injection, ${ }^{13} \mathrm{C}_{10}$-labelled ECN-5260 (CIL, MA, USA) was used as a recovery standard. The sample extraction, cleanup, instrumental analysis and quality control for PCNs determination are described in Supporting Information.

For the analysis of $\mathrm{HxCBz}$ and $\mathrm{PeCBz}$, the samples were spiked with known amounts of ${ }^{13} \mathrm{C}_{6}$-labelled EM-1725A (CIL, MA, USA) before extraction. The extraction and cleanup of $\mathrm{HxCBz}$ and $\mathrm{PeCBz}$ in stack gas samples followed the same procedure as that for the dl-PCBs. The samples were analyzed with an Agilent 7890A gas chromatograph equipped with a DB-5 MS capillary column $(30 \mathrm{~m} \times 0.25 \mathrm{~mm}$ i.d. $\times 0.25 \mu \mathrm{m})$ and interfaced to an Agilent 7000A Triple quadrupole mass spectrometer (GC/MS/MS). The data were acquired in Multiple Reaction Monitoring (MRM) mode as shown in the Table S2. The detailed sample instrumental analysis for $\mathrm{HxCBz}$ and $\mathrm{PeCBz}$ determination are described in Supporting Information.

In this study, the detection and quantification limits were defined as 3 and 10 times the signal-to-noise ratio $(\mathrm{S} / \mathrm{N})$, respectively. Blank experiments were carried out for every batch of samples. Analytical requirements were satisfied with the recovery of internal standards. The detailed LOD, LOQ and quality control for unintentional POPs determination were found in Tables S3 and S4.

\section{Results and discussion}

\subsection{Concentrations and TEQs of unintentional POPs released from the magnesium smelting process}

The concentrations of unintentional POPs in stack gas and fly ash of magnesium metallurgy facilities are shown in Table 1. For congeners with concentrations below the LOD, a value of LOD/2 was assigned for calculating the total concentration. WHO$\mathrm{TEF}_{2005}$ values by Van den Berg et al. were adopted for calculating the TEQs of PCDD/Fs and dl-PCBs (Van den Berg et al., 2006).

The sum WHO-TEQs of PCDD/Fs and dl-PCBs obtained from stack gas samples in this study for GOx and GRe were 10.7 and $13.8 \mathrm{pg} \mathrm{Nm}^{-3}$, respectively. These values are lower than the PCDD/Fs and dl-PCBs emissions from iron ore sintering plants in the UK (Aries et al., 2006), but quite comparable with those reported in the coking industry (5.2-94.1 pg WHO-TEQ $\mathrm{Nm}^{-3}$ ) 
Table 1

Concentrations and TEQs of unintentional POPs in stack gas and fly ash released from the magnesium smelting process ( $\mathrm{pg} \mathrm{Nm}^{-3}$ or $\mathrm{pg} \mathrm{g}^{-1}$ ).

\begin{tabular}{|c|c|c|c|c|}
\hline & \multicolumn{2}{|l|}{ Ox } & \multicolumn{2}{|l|}{$\underline{\operatorname{Re}}$} \\
\hline & $\operatorname{GOx}(n=6)$ & $\mathrm{SOx}(n=2)$ & $\operatorname{GRe}(n=3)$ & $\operatorname{SRe}(n=2)$ \\
\hline & Stack gas & Fly ash & Stack gas & Fly ash \\
\hline$\sum \mathrm{PCDD} / \mathrm{Fs}$ & 176 & 14.6 & 218 & 23.3 \\
\hline$\sum \mathrm{dl}-\mathrm{PCBs}$ & 126.5 & 24.6 & 3780 & 54 \\
\hline$\sum \mathrm{PCNs}$ & 93400 & 177 & 2470 & 490 \\
\hline $\mathrm{PeCBz}$ & 37000 & 273 & 3210 & 404 \\
\hline $\mathrm{HxCBz}$ & 22900 & 191 & 2270 & 278 \\
\hline $\begin{array}{l}\sum \text { WHO-TEQ } \\
\text { (PCDD/Fs and dl-PCBs) }\end{array}$ & 10.7 & 1.1 & 13.8 & 2.3 \\
\hline$\sum \mathrm{TEQ}$ (dl-PCNs) & 0.9 & 0.02 & 0.03 & 0.03 \\
\hline$\sum \mathrm{TEQ}(\mathrm{HxCBz})$ & 2.3 & 0.06 & 0.2 & 0.3 \\
\hline
\end{tabular}

(Liu et al., 2009), in primary copper smelting- $\mathrm{H}_{2} \mathrm{SO}_{4}$ production from stack gases ( 11 and $6.3 \mathrm{pg} \mathrm{T-TEQ} \mathrm{Nm}^{-3}$ ), primary iron production in a blast furnace (6.7 pg T-TEQ $\mathrm{Nm}^{-3}$ ) and foundry of spheroidal and cast iron (24.4 pg T-TEQ Nm ${ }^{-3}$ ) (Grochowalski et al., 2007). The sum WHO-TEQs of PCDD/Fs and dl-PCBs in fly ash were lower than that from stack gas released, which account for $10 \%$ of the total TEQ of PCDD/Fs and dl-PCBs, respectively. The average concentrations of stack gas and fly ash released from the magnesium plant were lower because of the use of purely raw materials as well as the high temperature of the Pidgeon process for magnesium smelting.

Understanding the emissions levels of PCNs to the atmosphere is important for regulation and source reduction. PCNs are formed as a combustion by-product similar to PCDD/Fs and dl-PCBs (Sakai et al., 1996; Noma et al., 2006). From Table 1, it can be seen that the concentrations of PCNs from stack gas emissions ranged from 2470 to $93400 \mathrm{pg} \mathrm{Nm}^{-3}$. For the GRe, the concentrations of PCNs in the samples from stack gas emissions were lower than the GOx. The concentrations of PCNs emitted during the magnesium smelting process were lower than those of industrial sources, such as incinerators, household combustion, the coking industry and non-ferrous metal smelting (Wyrzykowska et al., 2009; Ba et al., 2010; Liu et al., 2010). Although the concentrations of PCNs in the environmental matrices (Tolley and Blais, 2007; Ishaq et al., 2009) were detected from near magnesium plants, few data about PCNs emissions from stack gas and fly ash during the magnesium smelting process have been reported. There is already evidence that PCNs present a similar toxicity to PCDD/Fs (Villeneuve et al., 2000). The relative potency factors (RPFs) of individual PCN congeners to 2378-TeCDD have been estimated and used for toxic evaluations of PCNs (Guo et al., 2008; Liu et al., 2010). The TEQs of dioxin-like PCNs (dl-PCNs) from stack gas releases were in the range of $0.03-$ $0.9 \mathrm{pg}$ TEQ N ${ }^{-3}$ for the investigated magnesium plant. Although the total concentrations of PCNs were far more than the total 2378-PCDD/Fs, the TEQs of dl-PCNs were lower than those of PCDD/Fs because of the relatively low RPFs of dl-PCNs.

As for $\mathrm{HxCBz}$ and $\mathrm{PeCBz}$, studies of their emissions from stack gas during the magnesium smelting process have not been reported. Recently, studies on unintentional release of $\mathrm{HxCBz}$ and $\mathrm{PeCBz}$ from stationary sources have mainly focused on the coking industry, waste and coal combustion, metals production, and chemicals manufacture (Bailey, 2001; Hedman et al., 2006; Grochowalski et al., 2007; Liu et al., 2009). To explore the priority sources for applying the best available techniques/best environmental practices (BAT/BEP) to reduce the release of unintentional POPs, emissions levels of unintentional POPs during the magnesium smelting process were compared with those from other industrial sources. In this study, concentrations of $\mathrm{HxCBz}$ in stack gas ranged from 2270 to $22900 \mathrm{pg} \mathrm{Nm}^{-3}$, which are higher than that of the coking industry and primary iron production, but comparable with that of copper smelting with production of $\mathrm{H}_{2} \mathrm{SO}_{4}$, and aluminum scrap smelting with rotary furnaces and circulated fluidized bed (CFB) boilers (Grochowalski et al., 2007; Liu et al., 2009). According to van Birgelen's suggested RPF of $\mathrm{HxCBz}$, the TEQs of $\mathrm{HxCBz}$ were in the range of $0.06-2.3 \mathrm{pg} \mathrm{TEQ} \mathrm{Nm}^{-3}$ for the investigated magnesium plant (van Birgelen, 1998). Thus, $\mathrm{HxCBz}$ could add $1.7-16.5 \%$ to the total TEQ in the Pidgeon process of magnesium smelting.

As a new POPs listed in Stockholm Convention, PeCBz has attracted much attention with regard to sources and environmental levels. Although environmental levels of $\mathrm{PeCBz}$ have been reported in some studies (Dvorska et al., 2008; Bailey et al., 2009; Liu et al., 2009), but results from measurements of unintentional emissions of $\mathrm{PeCBz}$ from industrial sources are not available or limited. Existing studies on unintentional release of $\mathrm{PeCBz}$ have focused mainly on the coking industry, chemicals manufacture and waste incineration, from which reported emission levels of $\mathrm{PeCBz}$ from the coking industry and incineration were in the range $0.21-0.66 \mathrm{ng} \mathrm{Nm}^{-3}$ and 420-3900 $\mathrm{ng} \mathrm{Nm}^{-3}$, respectively (Bailey et al., 2009; Liu et al., 2009). According to Table 1 , concentrations of PeCBz in stack gas samples from the magnesium smelting process ranged from 3.21 to $37.0 \mathrm{ng} \mathrm{Nm}^{-3}$, which are far higher than that for the coking industry, as reported by Liu et al. (2009). However, the concentrations of $\mathrm{PeCBz}$ from fly ash were relatively low.

\subsection{Profiles of unintentional POPs emissions from the magnesium smelting process}

The congener profiles of 17 2378-substituted PCDD/Fs and 12 dl-PCBs are discussed as the fingerprints of PCDD/Fs and dlPCBs emissions, respectively, from the magnesium smelting plant. Fig. 1 shows the TEQs of PCDD/Fs, dl-PCBs and dl-PCNs levels in stack gas and fly ash samples collected from the magnesium smelting plant. A resemblance between the patterns might indicate similar formation mechanisms for PCDD/Fs during oxidization and reduction of magnesium.

In this study, Fig. 1(1a and 1b) clearly shows that 2,3,4,7,8-PeCDF and 1,2,3,7,8-PeCDD were two dominant congeners to PCDD/Fs, which account for more than $40 \%$ of the total TEQs of PCDD/Fs from the stack gas and fly ash. The TEQ PCDD/Fs congener pattern was similar to that obtained in other studies (Liu et al., 2009; Ni et al., 2009; Wang et al., 2009). In addition, TCDD showed a stronger relation to stack gas and fly ash because of its high toxicity. With respect to the distribution of concentrations, PCDD/Fs patterns in stack gas from the magnesium smelting process are usually characterized by higher fractions of 1,2,3,4,6,7,8-HpCDF, OCDF, 1,2,3,4,6,7,8-HpCDD and OCDD (Fig. S1(1a and 1b)). Many other studies also have confirmed that OCDD, HpCDD, HpCDF and OCDF are major contributors to the total 2378-substituted congeners or thermal-related sources (Wang et al., 2003; Zhu et al., 2008).

Homologue profiles of PCDD/Fs are normally correlated with different pathways of PCDD/Fs formation. In this study, the homologue profiles of PCDD/Fs are presented in Fig. 2(1a and 1b). The magnesium smelting process produced similar profiles compared to other thermal sources (Everaert and Baeyens, 2002; Suzuki et al., 2004). The distribution of homologue profiles in stack gas and fly ash varied unobvious from TCDD to OCDD. Furthermore, the PCDF shows a sharply downward tendency from low chlorinated furan to high chlorinated furan.

Different ratios of PCDFs to PCDDs $\left(\mathrm{R}_{\mathrm{DF} / \mathrm{DD}}\right)$ normally indicate different mechanisms of PCDD/Fs formation. For precursor formation of PCDD/Fs, some research has shown that $R_{\mathrm{DF} / \mathrm{DD}}$ is much lower than 1 (Luijk et al., 1994; Huang and Buekens, 1995). On the other hand, de novo synthesis normally requires an $R_{\mathrm{DF} / \mathrm{DD}}$ of 

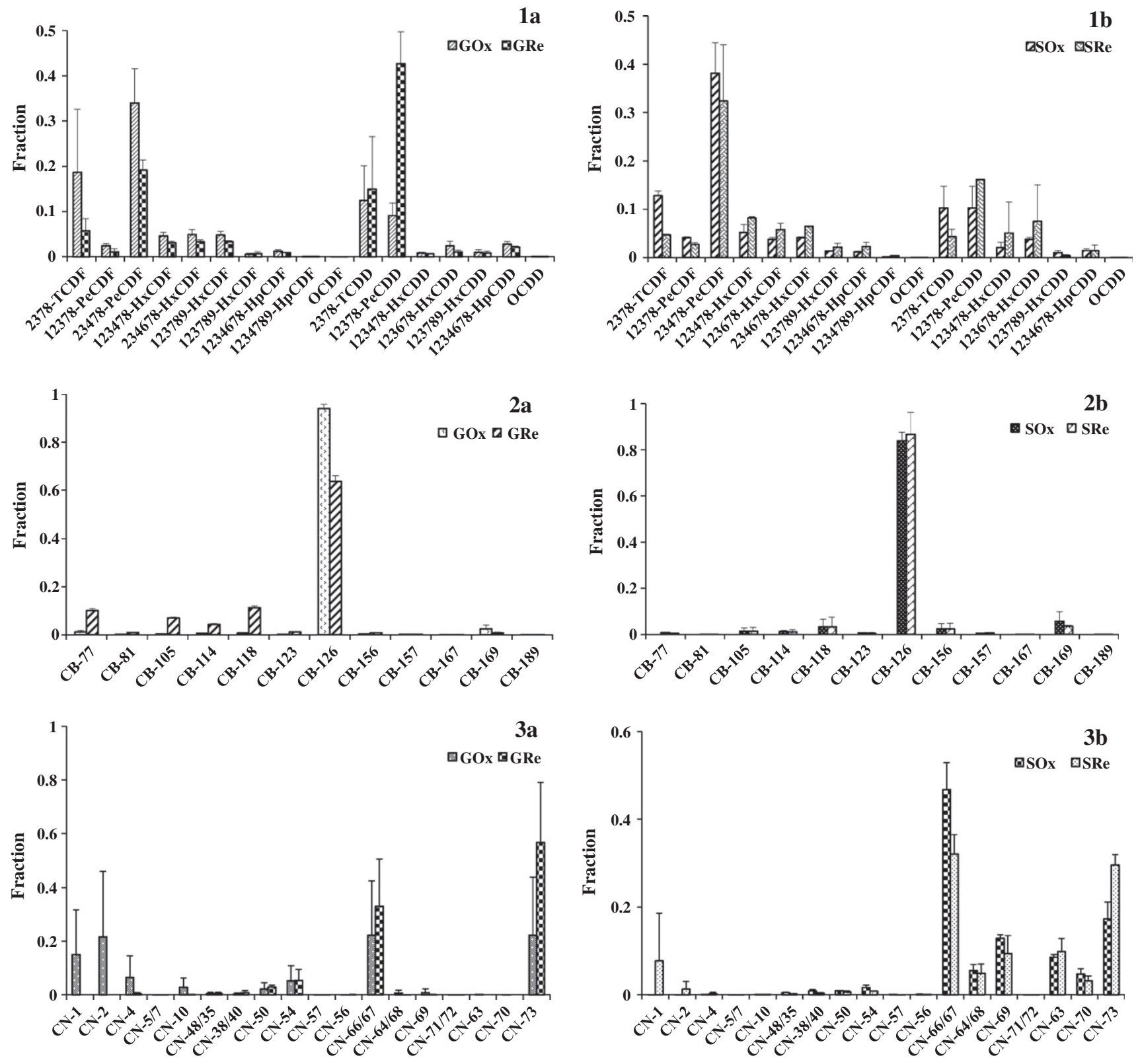

Fig. 1. TEQ congener patterns of PCDD/Fs, dl-PCBs and dl-PCNs in stack gas (a) and fly ash (b) from the magnesium smelting process.

greater than 1 (Everaert and Baeyens, 2002; Ni et al., 2009). The degree of chlorination is the sum of the percentages of the homologues multiplied by the numbers of substituted chlorines on the homologues (Everaert and Baeyens, 2002). The $\mathrm{R}_{\mathrm{DF} / \mathrm{DD}}$ values and the degree of chlorination are given in Table S5, from which it can be obtained that the ratio of PCDFs to PCDDs is greater than 1. Finally, de novo synthesis was assumed to be the main formation mechanism of PCDD/Fs during the magnesium smelting process, according to the characteristics and distribution of PCDD/Fs $\left(R_{\mathrm{DF} /}\right.$ $\mathrm{DD}>1)$.

With respect to dl-PCBs, CB-118 and CB-77 contributed over $70 \%$ of the total dl-PCBs in terms of concentration from stack gas and fly ash, followed by CB-105, as seen in Fig. S2(2a and 2b). The distributions of dl-PCBs TEQ are given in Fig. 1(2a and $2 b$ ). Although the percentage of CB-126 in the total dl-PCBs was less than $4 \%$ in terms of concentration, $\mathrm{CB}-126$ was the most predominant TEQ contributor, contributing more than $80 \%$ of the total dlPCB TEQ in oxidized stages from stack gas and fly ash (GOx and
SOx), because of its high TEF compared with the other dl-PCB congeners. However, in GRe, because CB-77, CB-105 and CB-118 had relatively high concentrations, the TEQ contribution accounted for $10 \%$.

In this study, the TEQ patterns of PCNs congeners in stack gas and fly ash are shown in Fig. 1(3a and $3 b$ ). The stack gas congener abundance patterns are quite different from the various stages of magnesium smelting. The most abundant congeners in stack gas from GOx are CN-1, CN-2, CN-66/67 and CN-73. Therefore, CN$66 / 67$ and $\mathrm{CN}-73$ were the two dominant stack gas congeners from the reduction stage (GRe), and account for more than $90 \%$ of the total TEQs of PCNs because of their relatively high RPFs compared with other PCNs congeners. In contrast, the TEQ patterns of PCN congeners in fly ash samples are quite similar, with $\mathrm{CN}-66 / 67$ and $\mathrm{CN}-73$ as the main contributors for all stages of the Pidgeon process of magnesium smelting.

A relatively consistent difference between the homologue distributions in stack gas and fly ash was observed in Fig. 2(2a and 

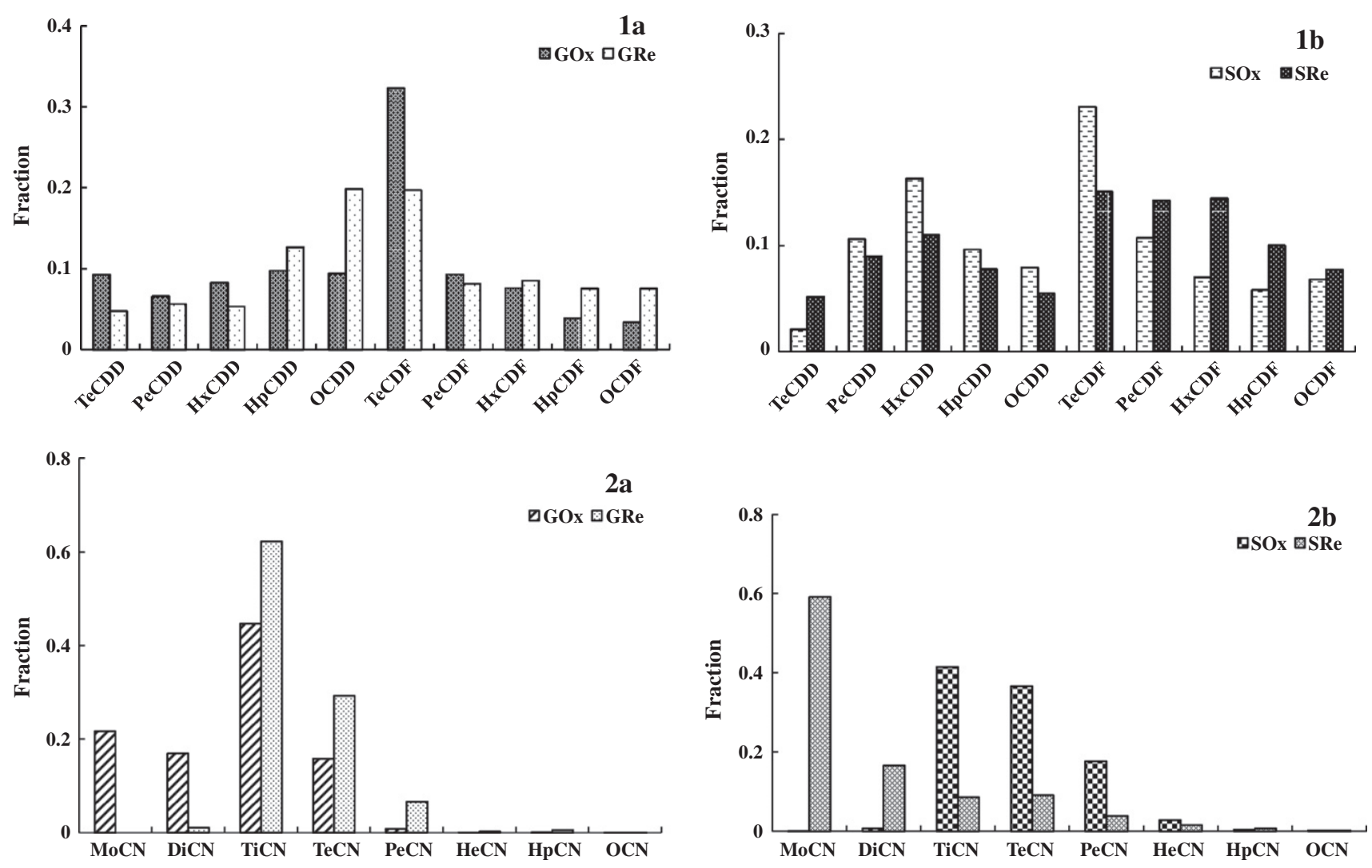

Fig. 2. $P C D D / F s$ and $P C N s$ homologue profiles in stack gas (a) and fly ash (b) from the magnesium smelting process.

2b). In stack gas from the oxidation stage (GOx), the lower chlorination PCNs are the dominant homologues, with mono- to tri-CNs making the most important contributions to the concentration. However, the tri- to penta-CNs were the main contributors to the concentration in the reduction stage (GRe). For fly ash from the reduction stage (SRe), the lower chlorination PCNs, like mono-CN and tera-CN, are the main dominant homologues, which account for around $87 \%$ of the total concentrations of PCNs. But in ash from the oxidation stage (SOx), tri-CN, tetra-CN and penta-CN are dominant homologues. The degrees of chlorination of PCNs ranged from 2.6 to 3.8 (Table S5), which were comparable with those from MSW combustion and the coking industry (Jansson et al., 2008; Liu et al., 2010). The results demonstrate that the average degree of chlorination from the oxidation stage in fly ash (3.8, SOx) was higher than that from the reduction stage $(2.8, \mathrm{SRe})$.

\subsection{Estimation of unintentional POPs emissions factors and total release from magnesium metallurgical facilities in China}

The following two equations were used to calculate emissions factors and total release of unintentional POPs.

$$
\begin{aligned}
\text { Emission factor }= & (\text { flow rate } \times \text { Concentration }) \\
& \div \text { metal output rate }
\end{aligned}
$$

Emissions amount $_{\text {pollutant }}=$ Emissions factor $_{\text {pollutant }}$

$$
\times \text { activity level }
$$

Emissions factors are important parameters for estimating the total emission of a given pollutant from a given source. In the magnesium smelting plant, fly ash is recycled to recover residual metal, and the final emissions amount in fly ash per ton of product is therefore very small. As a result, the emissions factors of fly ash are somewhat less than those of stack gas and were not calculated in this study. The emissions factors for unintentional POPs from magnesium metallurgical facilities in China were calculated using Eq. (1). The data are presented in Table 2.

Eq. (1) and Table 2 allowed us to establish specific emissions factors for the release of PCDD/Fs, dl-PCBs, PCNs, HxCBz and PeCBz to the atmosphere in the magnesium smelting process in China. The emissions factors of PCDD/Fs, dl-PCBs, dl-PCNs and $\mathrm{HxCBz}$ from stack gas of magnesium metallurgical facilities in China are 412, 18.6, 32.1 and $82.4 \mathrm{ng} \mathrm{TEQ} \mathrm{t}^{-1}$, respectively. The emissions factor of PCDD/Fs was about 7 times lower than the UNEP recommended generic emissions factor of $3000 \mathrm{ng} \mathrm{TEQ} \mathrm{t}^{-1}$ adopted for the thermal reduction process from magnesium smelting (UNEP Chemicals, 2005). Taking the output of primary magnesium in 2009 as an example, the output of primary magnesium in China reached about $501 \times 10^{3}$ tons (China Nonferrous Metals Industry Association, 2010). The emissions amounts of PCDD/Fs and dlPCBs, PCNs, $\mathrm{HxCBz}$ and $\mathrm{PeCBz}$ were estimated to be $12.6 \mathrm{~g}$ ( $0.46 \mathrm{~g}$ WHO-TEQ), $1651 \mathrm{~g}, 403 \mathrm{~g}$ and $652 \mathrm{~g}$, respectively, based on the mean emissions factors derived in this study. These data might

Table 2

\begin{tabular}{|c|c|c|c|c|}
\hline & \multicolumn{2}{|l|}{ GOx } & \multicolumn{2}{|l|}{ GRe } \\
\hline & $\mu \mathrm{g} \mathrm{t}^{-1}$ & ng TEQ $\mathrm{t}^{-1}$ & $\mu \mathrm{g} \mathrm{t}^{-1}$ & ng TEQ $t^{-1}$ \\
\hline $\mathrm{PCDD} / \mathrm{Fs}$ & 6.3 & 366 & 0.8 & 45.9 \\
\hline dl-PCBs & 4.5 & 14.2 & 13.8 & 4.4 \\
\hline PCNs & 3319 & 32.0 & 9.0 & 0.1 \\
\hline $\mathrm{PeCBz}$ & 1314 & - & 11.7 & - \\
\hline $\mathrm{HxCBz}$ & 814 & 81.7 & 8.3 & 0.7 \\
\hline Total & 5458 & 494 & 44 & 51 \\
\hline
\end{tabular}

Emission factors of unintentional POPs in concentration and TEQ from the magnesium smelting processes. 
be helpful for understanding levels of unintentional POPs produced by the magnesium industry and in developing a POPs inventory. More investigations on the emissions of unintentional POPs for the magnesium smelting industry in China need to be performed to obtain further information.

\section{Acknowledgments}

This study was supported by the National 973 program (2009CB421606), and the National Natural Science Foundation of China (21037003, 20921063).

\section{Appendix A. Supplementary material}

Supplementary data associated with this article can be found, in the online version, at doi:10.1016/j.chemosphere.2011.09.016.

\section{References}

Aries, E., Anderson, D.R., Fisher, R., Fray, T.A.T., Hemfrey, D., 2006. PCDD/F and "dioxin-like" PCB emissions from iron ore sintering plants in the UK. Chemosphere 65, 1470-1480.

Ba, T., Zheng, M.H., Zhang, B., Liu, W.B., Su, G.J., Xiao, K., 2009a. Estimation and characterization of PCDD/Fs and dioxin-like PCB emission from secondary zinc and lead metallurgies in China. J. Environ. Monitor 11, 867-872.

Ba, T., Zheng, M.H., Zhang, B., Liu, W.B., Xiao, K., Zhang, L.F., 2009b. Estimation and characterization of PCDD/Fs and dioxin-like PCBs from secondary copper and aluminum metallurgies in China. Chemosphere $75,1173-1178$.

Ba, T., Zheng, M.H., Zhang, B., Liu, W.B., Su, G.J., Liu, G.R., Xiao, K., 2010. Estimation and congener-specific characterization of polychlorinated naphthalene emissions from secondary nonferrous metallurgical facilities in China. Environ. Sci. Technol. 44, 2441-2446.

Bailey, R.E., 2001. Global hexachlorobenzene emissions. Chemosphere 43, 167-182.

Bailey, R.E., van Wijk, D., Thomas, P.C., 2009. Sources and prevalence of pentachlorobenzene in the environment. Chemosphere 75, 555-564.

Bao, R.H., Zhou, J.S., 2009. Situation of supply \& demand and coping strategies of the world for the magnesium. China Mining Magazine 18, 7-9.

Chen, W.K., Shi, J.W., 1995. Development for Nonferrous Metals (Light Metals). Central South University of Technology Press, Changsha, China. pp. 165-166.

China Nonferrous Metals Industry Association, 2010. The Primary Magnesium Production Level in China in 2009. <http://www.chinania.org.cn/web/website/ index_1009526702528110000.htm>.

China's NIP, 2007. National Implementation Plan for the Stockholm Convention on Persistent Organic Pollutants. <http://www.pops.int/documents/ implementation/nips/submissions/China_NIP_En.pdf $>$.

Dvorska, A., Lammel, G., Klanova, J., Holoubek, I., 2008. Kosetice, Czech Republic 10 years of air pollution monitoring and 4 years of evaluating the origin of persistent organic pollutants. Environ. Pollut. 156, 403-408.

Dyke, P.H., Amendola, G., 2007. Dioxin releases from US chemical industry sites manufacturing or using chlorine. Chemosphere 67, S125-S134.

Everaert, K., Baeyens, J., 2002. The formation and emission of dioxins in large scale thermal processes. Chemosphere 46, 439-448.

Fiedler, H., 2007. National PCDD/PCDF release inventories under the Stockholm convention on persistent organic pollutants. Chemosphere 67, S96-S108.

Grochowalski, A., Lassen, C., Holtzer, M., Sadowski, M., Hudyma, T., 2007. Determination of PCDDs, PCDFs, PCBs and HCB emissions from the metallurgical sector in Poland. Environ. Sci. Pollut. R 14, 326-332.

Guo, L., Zhang, B., Xiao, K., Zhang, Q.H., Zheng, M.H., 2008. Levels and distributions of polychlorinated naphthalenes in sewage sludge of urban wastewater treatment plants. Chinese Sci. Bull. 53, 508-513.

Hedman, B., Naslund, M., Marklund, S., 2006. Emission of PCDD/F, PCB, and HCB from combustion of firewood and pellets in residential stoves and boilers. Environ. Sci. Technol. 40, 4968-4975.
Huang, H., Buekens, A., 1995. On the mechanisms of dioxin formation in combustion processes. Chemosphere 31, 4099-4117.

Ishaq, R., Persson, N.J., Zebuhr, Y., Broman, D., Naes, K., 2009. PCNs, PCDD/Fs, and non-orthoPCBs, in water and bottom sediments from the industrialized Norwegian Grenlandsfjords. Environ. Sci. Technol. 43, 3442-3447.

Jansson, S., Fick, J., Marklund, S., 2008. Formation and chlorination of polychlorinated naphthalenes (PCNs) in the post-combustion zone during MSW combustion. Chemosphere 72, 1138-1144.

Li, H.W., Lee, W.J., Huang, K.L., Chang-Chien, G.P., 2007. Effect of raw materials on emissions of polychlorinated dibenzo-p-dioxins and dibenzofurans from the stack flue gases of secondary aluminum smelters. J. Hazard Mater. 147, 776784.

Liu, G.R., Zheng, M.H., Liu, W.B., Wang, C.Z., Zhang, B., Gao, L.R., Su, G.J., Xiao, K., Lv, P., 2009. Atmospheric emission of PCDD/Fs, PCBs, hexachlorobenzene, and pentachlorobenzene from the coking industry. Environ. Sci. Technol. 43, 91969201.

Liu, G.R., Zheng, M.H., Lv, P., Liu, W.B., Wang, C.Z., Zhang, B., Xiao, K., 2010. Estimation and characterization of polychlorinated naphthalene emission from coking industries. Environ. Sci. Technol. 44, 8156-8161.

Luijk, R., Akkerman, D.M., Slot, P., Olie, K., Kapteijn, F., 1994. Mechanism of formation of polychlorinated dibenzo-p-dioxins and dibenzofurans in the catalyzed combustion of carbon. Environ. Sci. Technol. 28, 312-321.

Ni, Y.W., Zhang, H.J., Fan, S., Zhang, X.P., Zhang, Q., Chen, J.P., 2009. Emissions of PCDD/Fs from municipal solid waste incinerators in China. Chemosphere 75, 1153-1158.

Noma, Y., Yamamoto, T., Giraud, R., Sakai, S., 2006. Behavior of PCNs, PCDDs, PCDFs, and dioxin-like PCBs in the thermal destruction of wastes containing PCNs. Chemosphere 62, 1183-1195.

Sakai, S., Hiraoka, M., Takeda, N., Shiozaki, K., 1996. Behavior of coplanar PCBs and PCNs in oxidative conditions of municipal waste incineration. Chemosphere 32, 79-88.

Suzuki, K., Kasai, E., Aono, T., Yamazaki, H., Kawamoto, K., 2004. De novo formation characteristics of dioxins in the dry zone of an iron ore sintering bed. Chemosphere 54, 97-104.

Tolley, C., Blais, J.M., 2007. Polychlorinated dibenzo-p-dioxin, polychlorinated dibenzofuran, and polychlorinated biphenyl accumulation in white-tailed deer (Odocoileus virginianus) near a magnesium smelter in Quebec, Canada. Environ. Toxicol. Chem. 26, 2650-2659.

UNEP Chemicals, 2005. Standardized Toolkit for Identification and Quantification of Dioxin and Furan. Releases. Geneva, Switzerland. <http://www.pops.int/ documents/guidance/toolkit/ver2_1/Toolkit-2005_2-1_en.pdf>.

van Birgelen, A.P.J.M., 1998. Hexachlorobenzene as a possible major contributor to the dioxin activity of human milk. Environ. Health Perspect. 106, 683-688.

Van den Berg, M., Birnbaum, L.S., Denison, M., De Vito, M., Farland, W., Feeley, M., Fiedler, H., Hakansson, H., Hanberg, A., Haws, L., Rose, M., Safe, S., Schrenk, D., Tohyama, C., Tritscher, A., Tuomisto, J., Tysklind, M., Walker, N., Peterson, R.E., 2006. The 2005 World Health Organization reevaluation of human and mammalian toxic equivalency factors for dioxins and dioxin-like compounds. Toxicol. Sci. 93, 223-241.

Villeneuve, D.L., Kannan, K., Khim, J.S., Falandysz, J., Nikiforov, V.A., Blankenship A.L., Giesy, J.P., 2000. Relative potencies of individual polychlorinated naphthalenes to induce dioxin-like responses in fish and mammalian in vitro bioassays. Arch. Environ. Contam. Toxicol. 39, 273-281.

Wang, L.C., Lee, W.J., Lee, W.S., Chang-Chien, G.P., Tsai, P.J., 2003. Effect of chlorine content in feeding wastes of incineration on the emission of polychlorinated dibenzo-p-dioxins/dibenzofurans. Sci. Total Environ. 302, 185-198.

Wang, Y.F., Chao, H.R., Wu, C.H., Wang, L.C., Chang-Chien, G.P., Yang, H.H., Lin, D.Y., Tsou, T.C., 2009. Emissions of polychlorinated dibenzo-p-dioxins and dibenzofurans from a heavy oil-fueled power plant in northern Taiwan. J. Hazard. Mater. 163, 266-272.

Wyrzykowska, B., Hanari, N., Orlikowska, A., Yamashita, N., Falandysz, J., 2009. Dioxin-like compound compositional profiles of furnace bottom ashes from household combustion in Poland and their possible associations with contamination status of agricultural soil and pine needles. Chemosphere 76 , 255-263.

Zhu, J.X., Hirai, Y., Yu, G., Sakai, S., 2008. Levels of polychlorinated dibenzo-p-dioxins and dibenzofurans in China and chemometric analysis of potential emission sources. Chemosphere 70, 703-711. 